\title{
Avaliação clínica e histopatológica de alo-transplante de bexiga em cães
}

\author{
[Clinical and histopathological evaluation of urinary bladder allotransplant in dogs] \\ M.W. Teixeira ${ }^{1}$, C.M.F. Rezende ${ }^{2}$, V.A. Silva Júnior ${ }^{1}$, M.J.D. Teixeira ${ }^{3}$ \\ E.C. Silva ${ }^{4}$, D.G. Barbosa ${ }^{4}$ \\ ${ }^{1}$ Universidade Federal Rural de Pernambuco - UFRPE \\ Av. Dom Manoel de Medeiros, $\mathrm{s} / \mathrm{n}$ \\ 52171-900- Recife - PE \\ ${ }^{2}$ Escola de Veterinária - UFMG - Belo Horizonte, MG \\ ${ }^{3}$ Aluna de pós-graduação - UFRPE - Recife, PE \\ ${ }^{4}$ Médica veterinária autônoma
}

\begin{abstract}
RESUMO
Testou-se a hipótese de o alo-transplante de bexiga devolver a capacidade estrutural e funcional desse órgão, usando-se 10 cães machos, saudáveis, submetidos à cistectomia parcial com preservação do trígono vesical. Utilizou-se o alo-transplante na reconstrução da vesícula urinária com acompanhamento dos animais durante 60 dias. Aos oito dias de pós-operatório, os cães apresentavam capacidade de contenção urinária e micção espontânea. Houve aumento gradativo do volume da vesícula urinária, alcançando, aos 60 dias, valores significativamente mais altos que os observados antes da cirurgia. Verificou-se integração tecidual com regeneração parcial na interface do transplante, caracterizada por reconstituição epitelial, proliferação fibroblástica, neoangiogênese e surgimento de fibras musculares lisas, aos 60 dias. Problemas como rejeição e obstrução uretral ocorreram em três cães. Conclui-se que o alo-transplante de bexiga em cães é viável e devolve a capacidade de repleção e as demais funções fisiológicas da vesícula urinária, ocorrendo regeneração parcial dos tecidos aos 60 dias de pós-operatório.
\end{abstract}

Palavras-chave: cão, alo-transplante, bexiga

\begin{abstract}
The hypothesis that urinary bladder allotransplant in dogs repairs the functional and structural capacity of this organ. Ten healthy male dogs were submitted to partial cystectomy, preserving the vesicle trigon. Allotransplant was used on the reconstruction of the urinary bladder and the animals were kept under observation for 60 days. On day seven after surgery, the dogs presented spontaneous capacity of contention and micturition. There was a gradual increase of the volume of the urinary bladder reaching to significantly higher values on day 60. Tissue integration with partial regeneration on the interface of the transplant, characterized by epithelial reconstitution, fibroblastic proliferation, neoangiogenesis and smooth muscular fibers appearance were observed on day 60. Problems as rejection and urethral obstruction occurred in three dogs. It is concluded that the allotransplant in dogs is viable, repairing the bladder capacity and other physiologic functions of the urinary bladder, although partial tissue regeneration is observed 60 days after operation.
\end{abstract}

Keywords: dog, allotransplantation, bladder

Recebido em 1 de fevereiro de 2005

Aceito em 2 de janeiro de 2007

E-mail: marcvet21@terra.com.br 


\section{INTRODUÇÃO}

O número de transplantes de órgãos e tecidos em humanos e animais tem crescido significativamente nos últimos anos, principalmente após o advento de técnicas modernas e mais seguras para a imunossupressão. $\mathrm{O}$ aprimoramento das técnicas operatórias proporcionou aos pacientes transplantados uma qualidade de vida aceitável e sobrevida mais longa. Apesar da crescente demanda de transplantes de órgãos nas medicinas humana e veterinária, até o momento não existe comprovação da viabilidade dos transplantes de bexiga.

Quando a capacidade de armazenamento da bexiga se torna comprometida, os transtornos funcionais podem ser graves e muitas vezes incapacitantes (Lepper et al., 2002). As cirurgias reconstrutivas da bexiga são essenciais na correção de desordens caracterizadas pela baixa capacidade de contenção e alta pressão intravesical (Piechota et al., 1998).

Nos cães, as indicações para a cirurgia reparadora da bexiga são os traumas graves, neoplasias e cistites intersticiais recorrentes. As cirurgias reconstrutivas da vesícula urinária buscam promover um reservatório de baixa pressão, com capacidade de continência, micção espontânea e mínimo resíduo pós-micção (Crandis et al., 1998).

Tradicionalmente tem se tentado a reconstrução da vesícula urinária, após cistectomia parcial, por meio da transposição de segmento autólogo de estômago ou intestino (Rigaud e Le Normand, 2004). Esses procedimentos, conhecidos como anastomose do trígono vesical, utilizados no homem, estão sujeitos a complicações, principalmente pela natureza histológica diferente entre o enxerto e a bexiga. As mais observadas são as fístulas, urolitíases, ausência de dilatação, contração do enxerto, neoplasias (Lepper et al., 2002), produção de muco e problemas metabólicos provenientes da absorção pela mucosa do tecido implantado (Fries et al., 1991).

Quando as neoplasias atingem o trígono vesical, a cistectomia radical é inevitável; nesses casos, tem-se optado pela confecção de uma neobexiga ortotópica feita com segmento de intestino autólogo (Rocha e Gomes, 2000). Em casos mais extremos, nos quais a ressecção do tumor é inviável ou o paciente está obstruído, pode-se fazer a derivação urinária, que é o desvio dos ureteres para a pele ou para o intestino grosso, o qual passa a funcionar como um reservatório (Stone et al., 1988).

Grande variedade de material sintético, biodegradável ou não, tem sido usado na reconstrução da bexiga. As membranas biológicas, como bexiga homóloga (Baiotto, 2001; Oliveira, 1999), pericárdio bovino (Kambic et al., 1992), placenta de humanos (Fishman et al., 1987) e submucosa de bexiga (Yoo et al., 1998), foram testadas na reconstrução da bexiga de cães com resultados variados e, às vezes, conflitantes.

A matriz acelular desponta como um método promissor na experimentação animal, embora sua utilização clínica em humanos ainda não esteja comprovada. As matrizes acelulares são preparadas de intestinos, estômago ou bexiga, por meio de manipulação mecânica e química, retirando-se as células do tecido e mantendo a matriz da membrana extracelular (Nuininga et al., 2004). Esses enxertos não causam rejeição, mas podem apresentar problemas semelhantes a outras membranas, como fístulas, formação de crostas e contração do implante (Zini et al., 2004).

A engenharia de tecidos, por meio da cultura celular autóloga, poderá ser, no futuro, uma opção viável para a resolução das falhas extensas da bexiga e outros órgãos, pois eliminaria por completo o problema da rejeição e diferenças celulares entre os tecidos implantados e o receptor (Zini et al., 2004). Porém, sua utilização em órgãos pluricelulares ainda não é possível devido a limitações técnicas (Oberpenning et al., 1999).

Segundo Teixeira (2004), o alo-transplante de bexiga urinária pode vir a ser uma alternativa eficaz na correção dos defeitos extensos ou incapacidade de dilatação da vesícula urinária, tanto em animais como nos seres humanos. Essa alternativa terapêtica pode trazer grandes benefícios para o homem e animais, desde que promova o recondicionamento da capacidade de armazenamento de urina e controle da micção. 
O objetivo deste trabalho foi estudar a viabilidade do alo-transplante de bexiga em cães em promover a regeneração total dos tecidos, o retorno da capacidade de armazenamento e a contenção e esvaziamento espontâneo da vesícula urinária.

\section{MATERIAL E MÉTODOS}

Foram utilizados 10 cães adultos jovens, com média de idade de dois anos, sem raça definida, sadios e com peso entre 10 e $15 \mathrm{~kg}$. Na escolha dos animais, consideraram-se as avaliações clínica, laboratorial (hemograma completo, dosagem de uréia e creatinina, urinálise, cultura urinária e testes para leishmaniose e erlichiose canina) e por imagem (ultra-sonografia, cistografia contrastada e pneumocistografia). Os animais escolhidos foram submetidos ao teste de reação cruzada para eritrócitos ("crossmatching") e separados em duplas conforme a compatibilidade.

Todos os animais foram submetidos a desverminação sete dias antes do procedimento cirúrgico, submetidos a banhos com produtos para combater ectoparasitas e acomodados em boxes individuais, onde receberam água e ração balanceada à vontade. Vinte e quatro horas antes da cirurgia, foi iniciada a terapia imunossupressora com ciclosporina na dose de $10 \mathrm{mg} / \mathrm{kg}$, a qual foi mantida a cada 24 horas por 30 dias.

Os animais foram operados aos pares, com procedimentos simultâneos no mesmo ambiente cirúrgico, sendo cada um doador e receptor. A técnica anestésica constou de pré-medicação com acepromazina $\quad 1 \% \quad(0,2 \mathrm{mg} / \mathrm{kg}) \quad$ pela via intramuscular; após 10 minutos, instalou-se um dispositivo intravenoso e procedeu-se à indução anestésica com tiopental sódico $(12,5 \mathrm{mg} / \mathrm{kg})$; a anestesia foi mantida com isofluorano vaporizado com oxigênio em circuito semifechado.

Utilizou-se a celiotomia retroumbilical paraprepucial para o acesso vesical. As bexigas foram exteriorizadas e esvaziadas por cistocentese. Colocaram-se dois reparos, com fio de náilon 3-0, posicionados imediatamente craniais à inserção de cada ureter, e um terceiro reparo na porção ventral do colo vesical. Os reparos serviram como guia para a cistectomia, que foi realizada $0,5 \mathrm{~cm}$ cranialmente à inserção dos ureteres, preservando apenas o trígono vesical. Após a ligadura das artérias vesicais caudais, as bexigas foram excisadas e imersas em solução de Ringer com lactato de sódio para retirar resquícios de sangue. Posteriormente, as mesmas foram suturadas no coto remanescente do outro animal em plano único, com fio monocryl 4-0 em padrão contínuo simples, envolvendo todas as camadas, exceto a mucosa. Ao término da sutura, procedeu-se à repleção da bexiga com solução salina para verificar possíveis vazamentos.

A celiorrafia foi realizada em padrão isolado simples, com fio monocryl 2-0, na linha alba; sutura contínua subcutânea, com o mesmo fio, para eliminação do espaço morto e sutura intradérmica com náilon 4-0. Fixou-se uma sonda uretral $n^{\circ} 06$ com "ponto chinês", a qual permaneceu por sete dias.

No período pós-operatório, os animais receberam diariamente antibiótico de largo espectro (enrofloxacina $5 \mathrm{mg} / \mathrm{kg}$ ) por quinze dias e antiinflamatório não-esteróide (cetoprofeno $1 \mathrm{mg} / \mathrm{kg}$ ) por quatro dias, ambos por via parenteral. Os animais foram mantidos em canil individual e acompanhados por 60 dias. Durante esse período, foram submetidos a exame clínico diário, acompanhamento laboratorial do quadro hematológico e urinário quinzenal, ultrasonografia semanal e cistografia aos 30 e 60 dias.

O volume de repleção máxima da bexiga foi mensurado antes da cirurgia e semanalmente até completar 60 dias; os dados foram avaliados estatisticamente por meio da regressão linear, como descrito por Sampaio (2002).

Após 60 dias da cirurgia, todos os animais foram novamente anestesiados a fim de se retirar fragmento da bexiga para exame histopatológico. O material foi obtido por uma incisão, com bisturi, na interface do implante com a bexiga remanescente, sendo o órgão novamente suturado com fio monocril 4-0. O fragmento foi fixado em formalina tamponada a $10 \%$ e processado rotineiramente para inclusão em parafina e coloração por hematoxilina-eosina. 


\section{RESULTADOS E DISCUSSÃO}

A abordagem cirúrgica permitiu uma exposição adequada da bexiga com visualização direta do trígono vesical. A colocação dos pontos próximos ao local de incisão da bexiga facilitou a tração e manutenção do coto após a incisão (Stone et al., 1996). No momento da ressecção da bexiga, ocorreu hemorragia que cessou após pinçamento e ligadura das artérias vesicais caudais.

Durante a sutura do enxerto, foram necessários dois reparos com fio para manter o enxerto em posição adequada e facilitar a orientação anatômica. Embora tenha se optado por uma sutura em única camada, não ocorreram extravasamentos durante a repleção imediata com solução salina, nem no pósoperatório. Estes achados não estão de acordo com a indicação de Liebermann-Meffert (2000), que afirmou ser essencial dupla sutura do enxerto e uso do omento maior em cirurgias reconstrutivas da bexiga para evitar vazamentos imediatos. Para Stone et al. (1996), a dupla camada de sutura proporciona maior resistência, embora diminua o lúmen da bexiga. Apesar de não ter se fixado o omento sobre a linha de sutura do enxerto, seis animais apresentaram aderência do omento à bexiga aos 60 dias (Fig. 1a).

Todos os cães apresentaram hematúria e polaciúria nos primeiros dias de pós-operatório, as quais regrediram totalmente aos cinco e 30 dias, respectivamente. A polaciúria é um sinal clínico encontrado nas afecções vesicais inflamatórias, onde há hiperatividade da musculatura detrusora (Nelson e Couto, 2003).

Após a retirada do cateter de espera no oitavo dia de pós-operatório, como recomendado por Stone et al. (1996), todos os animais apresentavam capacidade de contenção urinária e micção espontânea. Tais achados confirmam que a presença patente do trígono vesical mantém o mecanismo anti-refluxo e evita danos à inervação autonômica do colo vesical, a qual é responsável pelo mecanismo de continência e pela sensação de distensão vesical (Costello et al., 2000).

Três animais morreram, entre 35 e 50 dias de pósoperatório, apresentando sinais característicos de rejeição ao implante. Todos apresentaram hematúria recorrente, polaciúria-disúria, febre, caquexia, anorexia e linfocitose. No exame histológico da interface do tecido transplantado desses animais, foi observada a presença de infiltrado inflamatório mononuclear linfomacrofágico, bem como áreas de necrose na mucosa e na muscular. Tais achados sugerem a necessidade de imunossupressão por tempo mais longo que trinta dias. Embora a determinação da compatibilidade linfocitária (DLA) seja importante na seleção dos possíveis doadores (Pereira et al., 2002), neste estudo não foram realizados tais testes. Estudos específicos para determinar a presença dos complexos de histocompatibilidade principal (HCM) na vesícula urinária dos cães precisam ser ainda realizados.

A cistografia aos trinta dias revelou uma bexiga diminuída de tamanho e disforme. Seis animais apresentaram área de estenose no local da sutura, dando à cúpula vesical um aspecto de divertículo. Porém, aos 60 dias, o volume vesical aumentou significativamente e não mais se observou a estenose. A causa da estenose temporária pode ter ocorrido pela presença do fio que foi utilizado em padrão de sutura contínuo. Este achado não foi observado em nenhuma literatura consultada.

Os animais foram submetidos à avaliação semanal pela ultra-sonografia (Fig. 1d) quanto ao volume da bexiga, aspecto da parede (integridade e espessura) e aspecto do conteúdo urinário. A bexiga foi distendida com solução fisiológica estéril via sonda até constatação de resistência, para avaliação de sua capacidade volumétrica e complacência. $\mathrm{O}$ volume mostrou-se em quantidade diminuída nos primeiros 30 dias após a cirurgia. Houve aumento gradativo do volume da vesícula urinária, alcançando, aos 60 dias, valores mais altos que os determinados antes da cirurgia (Fig. 1c).

A parede da vesícula urinária apresentou imagem ultra-sonográfica de espessamento e com maior ecogenicidade, sem, contudo, perder a integridade. Havia imagem compatível com estenose entre a bexiga remanescente e o enxerto após trinta dias de pós-operatório, a qual desapareceu nos exames subseqüentes. Nos exames ultra-sonográficos após 30 dias, observou-se a formação de uma estrutura ecogênica no lúmen da bexiga em cinco animais. Macroscopicamente, possuía aspecto membranoso, com movimentação livre na urina e pontos de aderência na mucosa. Após avaliação histológica, observou-se que esta era remanescente do desprendimento do urotélio da porção transplantada da bexiga.

Por meio da regressão linear, observou-se aumento significativo do volume da bexiga com crescimento médio diário de 0,30ml (Fig. 2). 


\section{Teixeira et al.}
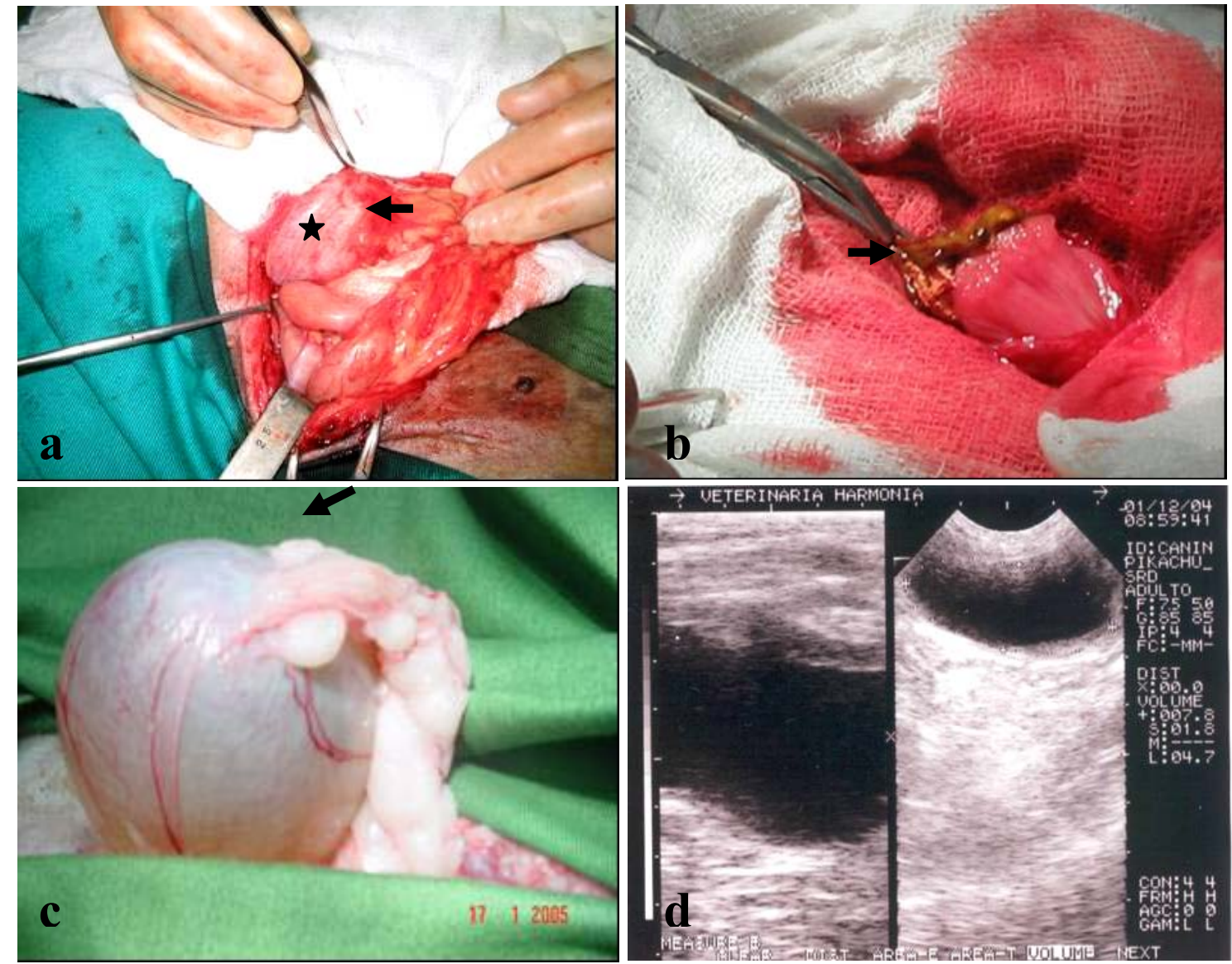

Figura 1. Bexiga de cão, transplantada, aos 60 dias de pós-operatório e respectiva ultra-sonografia. a) aderência do omento na neobexiga (seta) e aspecto da bexiga vazia (asterisco); b) processo de necrose da mucosa do implante com migração do urotélio sob a mesma (seta); c) integração completa do implante ao leito receptor, restando apenas aderência do omento (seta) à vesícula urinária; d) ultra-sonografia, paredes delgadas e volume vesical dentro da normalidade.

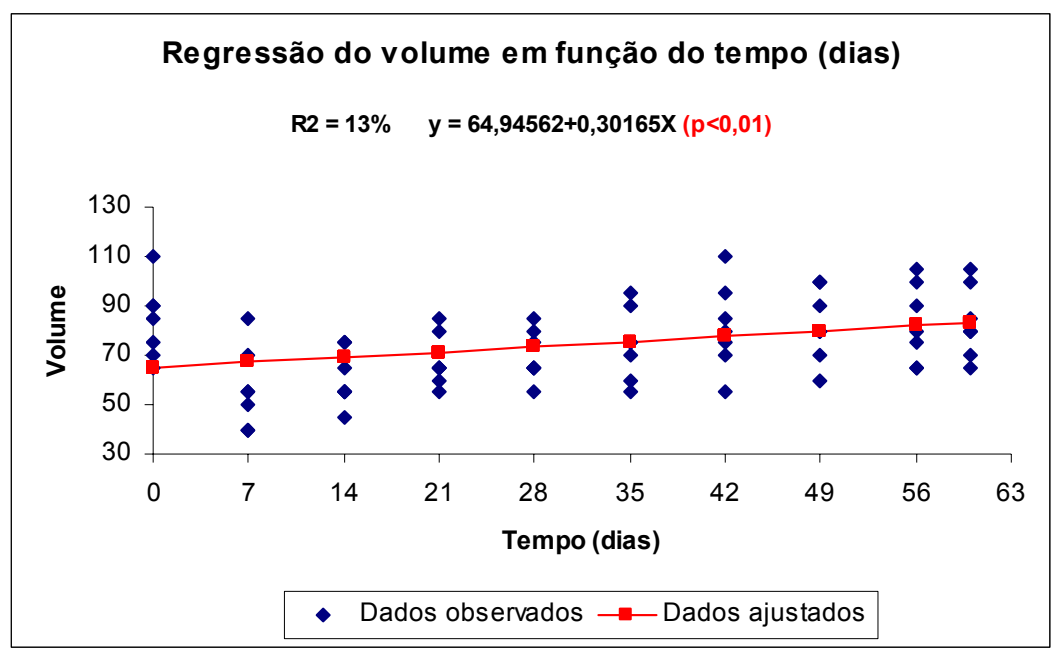

Figura 2. Análise da regressão linear do volume da bexiga após alo-transplante em cães. 
Durante o procedimento cirúrgico para retirada de fragmento para avaliação histológica aos 60 dias, confirmou-se a presença de material totalmente livre ou aderido à mucosa da neobexiga em quatro animais (Fig. 1b). O exame histológico revelou tratar-se do urotélio desprendido do enxerto. Essa alteração pode ter sido proveniente da vascularização insuficiente. Baiotto (2001) observou a mesma alteração quando utilizou cólon descendente autólogo na reconstrução da bexiga em cadelas e considerou ser decorrente da necrose parcial do enxerto.

Um cão teve que ser submetido a uma segunda cirurgia aos 45 dias, pois o fragmento desprendido da mucosa vesical obliterou a uretra causando retenção urinária. Após a retirada cirúrgica do material, o animal voltou a urinar normalmente. Os cães machos são conhecidos pela facilidade em desenvolver quadro de obstrução uretral, atribuída à anatomia da uretra.

Houve migração cranial da interface da neobexiga com a bexiga nativa, evidenciando a dilatação compensatória da porção remanescente (Kockum et al., 1999). O enxerto serviu como substrato para a migração do tecido vesical (Kambic et al., 1992), mas a presença de resquícios do tecido implantado mostra que a regeneração não foi completa aos 60 dias.

A litíase vesical é um achado comum quando se faz a reconstrução da bexiga. Segundo Cubillana et al.(1998), o pH urinário alcalino, a infecção recorrente e o resíduo pós-miccional, e o contato da urina com o material de sutura podem ser os fatores mais importantes na etiologia da litíase vesical pós-cirúrgica. Huselhuhn et al. (1994) afirmaram que alterações como cristalúria e presença de depósito de sais podem ocorrer precocemente, após cirurgias reparadoras da bexiga. Neste experimento, porém, os animais não apresentaram sinais compatíveis com tais alterações, aos 60 dias de pós-operatório.

$\mathrm{Na}$ avaliação histológica da interface do implante com a bexiga remanescente, a mucosa estava com epitélio hiperplásico, contudo sem a presença de células globosas típicas de epitélio polimórfico de transição. Notou-se também intensa proliferação fibroblástica (Fig. 3a). Em algumas áreas de mucosa, os vasos estavam congestos, sendo possível observar focos inflamatórios linfoplasmocitários discretos, difusos e rodeando os vasos (Fig. 3b). A lâmina própria de tecido conjuntivo possuía infiltrado inflamatório mononuclear linfoplasmocitário (Fig. 3d) com arranjo vascular típico de tecido de granulação, áreas de hemorragia e depósitos de hemossiderina (Fig. 3c). Na adventícia da bexiga, constatou-se a presença de fio encapsulado com áreas adjacentes de fibrose e infiltrado inflamatório (Fig. 3e). Os achados histopatológicos caracterizam o processo de rejeição inicial do transplante, o qual provavelmente decorreu em virtude da retirada precoce da imunossupressão. Entretanto, observaram-se regeneração e integração parcial dos tecidos na interface do transplante, caracterizada por proliferação fibroblástica, neoangiogênese e surgimento de fibras musculares lisas (Fig. 3f). Baiotto et al. (2001), em experimento com bexiga conservada em glicerina por 30 dias, observaram a ausência de reepitelização da porção enxertada da bexiga aos 60 dias. Os mesmos autores encontraram, ainda, granulomas na sutura e mineralização do tecido, ora sob forma de granulações, ora sob forma de placas. 

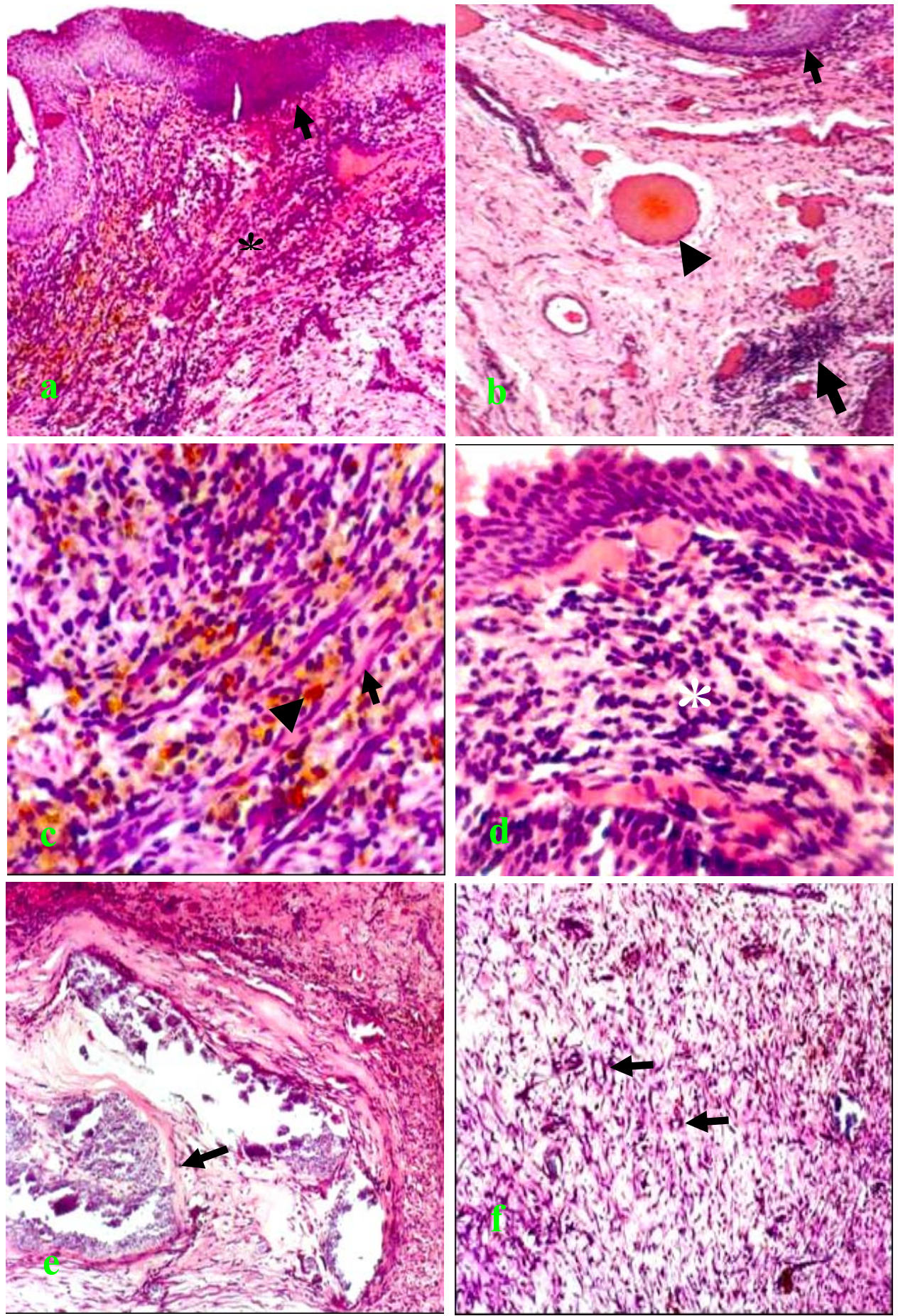

Figura 3. Bexiga de cão, transplantado, aos 60 dias de pós-operatório. HE. a) mucosa com epitélio hiperplásico (seta) e lâmina própria de tecido conjuntivo com infiltrado inflamatório $(*), 100 \mathrm{X}$; b) mucosa com epitélio hiperplásico (seta), lâmina própria espessada, vasos congestos (cabeça de seta) e discreto foco inflamatório (seta larga), 100X; c) detalhe da lâmina própria, presença de vasos (seta) entremeados por infiltrado inflamatório e pigmento de hemossiderina (cabeça de seta), 400X; d) detalhe de mucosa com infiltrado inflamatório linfoplasmocitário $(*)$, 400X; e) adventícia com fio encapsulado (seta); 100X; f) reação fibroblástica e fibras musculares lisas próximas a vasos neoformados (seta), 100X. 


\section{CONCLUSÃO}

O alo-transplante de bexiga em cães é viável, devolve a capacidade de repleção e as demais funções fisiológicas da vesícula urinária, mas a regeneração dos tecidos é parcial aos 60 dias de pós-operatório. A imunossupressão, com ciclosporina, por 30 dias, demonstrou ser insuficiente para evitar os episódios de rejeição ao implante em três cães.

\section{REFERÊNCIAS BIBLIOGRÁFICAS}

BAIOTTO, G.C. Reconstrução vesical em cães após cistectomia supratrigonal utilizando cólon descendente ou bexiga homóloga conservada em glicerina. 2001. 54f. Dissertação (Mestrado) - Universidade Federal de Santa Maria, Santa Maria, RS.

COSTEllo, A.J.; CROWE, H.; AGARWAL, D. Supratrigonal cystectomy and ileocystoplasty in management of intersticial cystititis. Austr. N. Z. J. Surg., v.70, p.34-38, 2000 .

CRANDIS, A.; NESTORIDIS, G.; DELAKAS, D. et al. Bladder autoaugmentationin the rabbit using depithelialized segments of small intestine, stomach and lyophilized human dura mater. Br. J. Urol., v.81, p.62-67, 1998.

CUBILLANA, P.L.; GÓMES, G.G.; GÓMEZ J.R., et al. Incidencia y factores de riesgo para la formación litiásica em pacientes sometidos a cistoplastias de ampliación o sustitución com intestino. Arch. Esp. Urol., v.51, p.347$352,1998$.

FISHMAN, I.J.; FLORES, F.N.; SCOTT, F.B., et al. Use of fresh placental membranes for bladder reconstruction. Urology, v.138, p.1291-1294, 1987.

FRIES, C.; BINNINGTON, A.G.; VALLI, V.E. et al. Enterocystoplasty with cystectomy and subtotal intracapsular prostatectomy in the male dog. Vet. Surg., v.20, p.104-112, 1991.

HUSELHUHN, G.; KROPP, K. A.; KECK, R.W. Photochemical ablation of intestinal mucosa for bladder augmentation. J. Urol., v.152, p.2267-2271, 1994.

KAMBIC, H.; KAY, R.; CHEN, J.F., et al. Biodegradable pericardial implants for augmentation: a 2.5 year studying dogs. J. Urol., v.148, p.539-543, 1992.

KOCKUM, C. C.; WÍLLEN, R.; MALMFORS, G. Bladder augmentationwith different forms of intestinal grafts: an experimental study in the pig. BJU Int., v.1, p.305-311, 1999.

LEPPER, F.G.O.; RAMOS, T.M.; TRINDADE FILHO, J.C.S et al. Bladder augmentation in rabbits with anionic collagen membrane, with or without urotelial preservation. Cistometric and hystologic evaluation. Int. Braz. J. Urol., v.28, p.464-470, 2002.

LIEBERMANN-MEFFERT, D. The greater omentum: anatomy, embryology and surgical applications. Surg. Clin. N. Am., v.80, p.275-293, 2000.

NELSON, R.W.; COUTO, C.G. Small animal internal medicine. 3.ed. St. Louis: Mosby, 2003. 1362p.

NUININGA, J.E.; MOERKERK, H.V.; HANSSEN, A. et al. A rabbit model to tissue engineer the bladder. Biomaterials, n.25, p.1657-1661, 2004.

OBERPENNING, F.; MENG, J.; YOO, J.J. et al. De novo reconstitution of a functional mammalian urinary bladder by tissue engineering. Nat. Biotechnol., v.17, p.133-134, 1999.

OLIVEIRA, L.O. Implante homógeno de bexiga conservada em glicerina a $98 \%$ para reparo da bexiga de cães. 1999. $72 \mathrm{f}$ Dissertação (Mestrado) - Universidade Federal de Santa Maria, Santa Maria, RS.

PEREIRA, L.C.; ARAUJO, R.B.; GHELLER, V.A. et al. Colonic-trigonal anastomosis in dogs. Arq. Bras. Med. Vet. Zootec., v.54, p.390-395, 2002.

PIECHOTA, H.J.; DAHMS, M.P.; GLEASON, L.S. et al. Functional rat bladder regeneration through xenotransplantation of the bladder acellular matrix graft. Br. J. Urol., v.81, p.548-559, 1998.

RIGAUD, J., LE NORMAND, L. Augmentation enterocystoplasty. Ann. Urol., v.38, p.298-310, 2004.

ROCHA, T. F.; GOMES, M.C. Derivações urinárias In: Guia prático de urologia. Disponível em $<$ http://www.sbu-mg.org.br/guia/guia\%20pratico\%20\%20cap\%2032.pdf $>$ Acessado em 29 jul. 2004.

SAMPAIO, I.B.M. Estatística aplicada à experimentação animal. 2.ed. Belo Horizonte: FEPMVZ, 2002. p. 265.

STONE, E.A.; GEORGE, S.D.; PAGE, R.L. Partial cystectomy for urinary bladder neoplasia: surgical technique and outcome in 11 dogs. J. Small Anim. Pract., v.37, p.480-485, 1996.

STONE, A.E.; WITHROW, S.J.; PAGE, R.L. et al. Ureterocolonic anastomosis in ten dogs with transitional cell carcionoma. Vet. Surg., v.17, p.147-153, 1988.

TEIXEIRA, M.W. Transplante de bexiga - Medicina veterinária a serviço da medicina humana. $V \& Z-V e t$. Zootec., v.22, p.3-4, 2004

YOO, J.J.; MENG, J.; OBERPENNING, F. Bladder augmentation using allogenic bladder submucosa seeded with cells. Urology, v.51, p.221-225, 1998.

ZINI, L.; YIOU, R.; LECOEUR, C. et al. Tissue engineering in urology. Ann. Urol., v.38, p.266-274, 2004. 